\title{
Investigation of humoral and cellular immunity hydatid in pathology in people
}

\author{
Hasmik Zanginyan, Laura Hovsepyan*and Gayane Ghazaryan \\ Laboratory of Molecular Membranology, Institute of Molecular Biology, National Academy of Sciences, Armenia
}

\begin{abstract}
This work was carried out to determine the nature of the immunological response of immunoglobulins, cytokines in liver echinococcosis and their changes after echinococcectomy.
\end{abstract}

\section{Introduction}

Echinococcosis (LE) is an important problem in Medical Parasitology. Hydatid disease of the liver causes profound functional changes in liver leading to local complications associated with liver failure as well as loss of vitality of human body in general.

Parasitic infestations trigger immune defense mechanisms, both humoral and cellular. The nature of the immune response induced by the presence of hydatid cysts in the liver is mainly determined by their morphological and biological characteristics, based on the interaction of various types of immune cells.

The pathogenesis of hepatic echinococcosis is also associated with the growth of the inflammatory reaction, which triggers a number of immune-defense mechanisms, both humoral and cellular. Therefore studying of the role of immune mediators of inflammation in patients with liver echinococcosis is undoubtedly of theoretical and practical interest. These tests help to clarify the mechanisms of immune disorders in hydatid cyst of the liver for developing additional diagnostic and preventive criteria.

This research clarifies the pathogenesis of some postoperative complications, which will allow improving their pharmacotherapy.

Immune response is formed not immediately, but within a certain period of time. They are much more efficient, longer and aimed at the elimination of the parasite of a certain type. The main factor specific protection is the development of antibodies. Antibodies with worms are generally four classes of immunoglobulins - IgG, IgM, IgE, IgA [1]. The first line of defense forms the macrophages, neutrophils, eosinophils and platelets. Macrophages secrete substances that regulate the inflammatory response. Some of them IL-1, IL-2, TNF- $\alpha$ and colony - stimulating factors enhance immunity by activating other cells or stimulating their proliferation. Cytokines such as IL-10, prostaglandins, and TGF- $\beta$, may exhibit anti-inflammatory and immunosuppressive properties, as well as to give the hepatocyte resistance to parasites [2-4].

Once infected with Echinococcus rapidly worse all effector functions of macrophages. Tissue macrophages trigger the synthesis of cytokines, which activate the function of all immune cells express their receptors, increase the synthesis of endothelial cells and leukocytes adhesion molecules and the synthesis of growth factors [3]. Specific activation of these cells induce cytokines secreted T-cells (IFN-g, GMCSF, IL-3 and IL-4), but macrophages can be activated independently from T-cells.

The aim of this work was the elucidation of the nature of the immunological reaction, the concentration of immunoglobulins, cytokines in hydatid cyst of the liver and their changes after cystectomy.

\section{Material and methods}

The study was performed in patients with liver echinococcosis of people admitted to the hospital. All patients during preoperative examination to clarify the diagnosis, size, localization and focal formations were performed by CT scan and abdominal ultrasound. Blood samples were taken 1 day before surgery and after surgery at 3 , 5, 10 days. The control was the donor. Fence whole blood produced fasting from a peripheral vein into tubes with EDTA, for some studies, with subsequent centrifugation and separation of plasma. To determine the concentration of cytokines in peripheral blood using a commercial ELISA kit (Diaclone, France). Specific proteins (immunoglobulins) were determined on an automatic biochemical analyzer COBAS INTEGRA 400 PLUS turbidimetric technique. Immunoturbidimetry is a quantitative measurement of the concentration of specific proteins by the change in turbidity of the solution during the reaction antigenantibody. Mathematical data processing was performed using the computer program "SigmaPlot 11.0" with the use of special guides in medical and biological statistics.

\section{Results and discussion}

The formation of cytokines is an important element in the maintenance of homeostasis. However, if there is a hyperproduction of cytokines can damage the liver. In patients with hydatid cyst of the

*Correspondence to: Laura Hovsepyan, Laboratory of Molecular Membranology, Institute of Molecular Biology, National Academy of Sciences, Armenia, Tel: +37410243609, E-mail: lhovsep@mail.ru

Key words: echinococcosis, immunoglobulins, cytokines

Received: November 24, 2016; Accepted: December 29, 2016; Published: January 03, 2017 
Table 1. The contents of cytokines in serum of patients with hepatic echinococcosis before and after surgery.

\begin{tabular}{|l|c|c|c|c|c|}
\hline & control & before surgery & $3^{\text {rd }}$ day after surgery & $\mathbf{6}^{\text {th }}$ day after surgery & $\mathbf{1 0}$ days after surgery \\
\hline TNF-a & $10.8 \pm 2$ & $44 \pm 3.8^{*}$ & $48 \pm 4.1^{* *}$ & $54 \pm 4.6^{* *}$ \\
\hline IL- 8 & $11.5 \pm 2.1$ & $54.5 \pm 4.7^{* *}$ & $62.1 \pm 5.3^{* *}$ & $56.2 \pm 4.8$ \\
\hline IL- 6 & $25.15 \pm 4.7$ & $40.37 \pm 3.5^{*}$ & $177.9 \pm 15.3^{* *}$ & $55.7 \pm 4.8$ & $137.3 \pm 11.8^{* *}$ \\
\hline
\end{tabular}

Note: $* \mathrm{P}<0.05, * * \mathrm{P}<0.001$

1. the significance of differences compared to control:

2. the significance of differences to the 1

3. the significance of differences compared to the 2

4. the significance of differences compared to the 3

The activity of humoral immunity was evaluated on the basis of the level of immunoglobulins.

Table 2. The level of immunoglobulins in the peripheral blood when liver echinococcosis before and after surgery.

\begin{tabular}{|c|c|c|c|c|c|}
\hline Index & The norm & Control $(n=6)$ & $\begin{array}{l}\text { To treatment }(n=12) \\
1\end{array}$ & $\begin{array}{c}\text { On3days } \\
2\end{array}$ & $\underset{3}{\text { On10 days }}(n=12)$ \\
\hline $\operatorname{Ig} \mathrm{A}(\mathrm{g} / \mathrm{l})$ & $0.7-4.0$ & $2.52 \pm 0.5$ & $5.56 \pm 0.5^{* *}$ & $2.2 \pm 0.2 * *$ & $2.34 \pm 0.2 *$ \\
\hline $\operatorname{Ig~} \mathrm{G}(\mathrm{g} / \mathrm{l})$ & $8-18$ & $15.05 \pm 2.8$ & $20.6 \pm 1.8^{*}$ & $17.32 \pm 1.5$ & $12.25 \pm 1^{*}$ \\
\hline $\operatorname{Ig} \mathrm{E}(\mathrm{MU})$ & $10-20$ & $10.69 \pm 2$ & $337.6 \pm 29 * *$ & $183.9 \pm 16^{* *}$ & $33.31 \pm 2.9^{* *}$ \\
\hline $\operatorname{Ig} \mathrm{M}(\mathrm{g} / \mathrm{l})$ & $0.4-2.3$ & $1.74 \pm 0.3$ & $1.85 \pm 0.2$ & $3.096 \pm 0.3^{*}$ & $1.63 \pm 0.1^{* *}$ \\
\hline
\end{tabular}

Note: $* \mathrm{P}<0.05, * * \mathrm{P}<0.001$

1. the significance of differences compared to control:

2. the significance of differences to the 1

3. the significance of differences compared to the 2

liver compared with the control group observed a change in the levels of TNF-a in serum: a significant increase to the surgical treatment and increase on day 6 after surgery. TNF- $\alpha$, refers to the proinflammatory cytokines secreted by Kupffer cells in hepatitis, in low concentrations it plays an important role in the regulation of the immune response and tissue homeostasis, but in high concentrations causes a pathological endocrinopathies action, causing the microvascular hypercoagulability and hemodynamic disorders. A significant increase in the content of TNF- $\alpha(44.0 \pm 3.8 \mathrm{PG} / \mathrm{ml}$ versus $10.8 \pm 2 \mathrm{PG} / \mathrm{ml}$ in healthy) in the serum of patients with electronic signature attests to the importance of the indicated cytokine in mechanisms of inflammation and cellular immune responses. A study of the concentrations of IL- 6 and IL-8 allowed to detect an increase in patients with hepatic echinococcosis before operation (Table 1). The increased levels of IL-6 in blood is observed in many pathological conditions (severe inflammation, infection, trauma, autoimmune diseases) the possibility of using IL-6 as a marker for early assessment of severity of pathological processes.

From the data presented it is clear that, in monitoring the level of IgA in serum was $2.52 \pm 0.5 \mathrm{~g} / \mathrm{l}$, in patients with hepatic echinococcosis before operation revealed a significant increase in the level of $5.56 \pm 0.5$ $\mathrm{g} / \mathrm{l}$ (Table.2). On the 3rd day after the operation, the IgA level returned to normal and remained until the 10th day after surgery - of $2.34 \pm 0.2$ g/L. EP patients' number before treatment Ig $M$ corresponds to the physiological norm, and observed a significant increase in IgA, Ig G and Ig E. Production of IL-6 increases, which, along with the normal level of production of Ig $\mathrm{M}$, is a compensatory mechanism aimed at reducing production of TNF- $\alpha$ antagonist is IL- 6 . On the $3^{\text {rd }}$ day after cystectomy observed normalization of level of Ig A and Ig E at higher levels of Ig M, which together with higher levels of IL-6 indicates the activation of the humoral link of immunity. The level of Ig $\mathrm{G}$ in the control group was made up of $15.05 \pm 2.8 \mathrm{~g} / \mathrm{l}$, in patients identified a high level of $20.6 \pm 1.8$ $\mathrm{g} / \mathrm{l}$ on days 3 and 10 days level of Ig $\mathrm{G}$ in the blood serum remained in the normal range. Significant changes have been Ig E. Donors this figure composes of $10.69 \pm 2 \mathrm{IU}$ (Table 2), and in patients with hydatid cyst of the liver it increased to $337.6 \pm 29$ IU. On the 3rd day the level of Ig E gradually decreased, but for 10 days he remained above normal. Despite the development of immune responses, Echinococcus capable of long time to persist in the body because it has strong immunosuppressive properties and antigens, shared antigens with the host, loss of the receptor for the development of effector immune mechanisms. All this leads to chronic course of the disease and creates a risk of other infections and cancer diseases.

\section{Conclusions}

Thus, the obtained data indicate that the hydatid cyst of the liver develops an imbalance of immunological parameters, indicating a decrease in resistance of the organism and the development of immune deficiency. The pathogenesis of hydatid cyst of the liver associated with the development of the inflammatory response that causes activation of a number of immunopathological am protective mechanisms, and humoral and cellular.

The Study of concentration of cytokines in combination with other research can significantly enhance the diagnosis of the functional state of the liver, will help to predict the postoperative period and draw up a programme of postoperative rehabilitation. The validity of the prediction of the outcome of the disease increases significantly in the study of cytokine profile in dynamics - before, during and after the surgical allowance.

\section{References}

1. Vinogradov AB (2006) Medicinskaya parazitologiya. Rostov N/D "Feniks".

2. Lukina EA (1998) Sistema mononuklearnih fagocitov i biologicheskie effekti provospalitelnih citokinov. Ros jurn gastroenterol gepatol i koloproktol 9: 1317.

3. Shichkin VP (1998) Patogeneticheskoe znachenie citokinov i perspektivi citokinovoi/ anticitokinovoi terapii. Immunologiya: S.913.

4. Abramson JS, Mills EL (1988) Depression of neutrophyl fimction induced by viruses and its role in secondary microbial infections. Rev Infect Dis 10: 326-341.

Copyright: (C2017 Zanginyan H. This is an open-access article distributed under the terms of the Creative Commons Attribution License, which permits unrestricted use, distribution, and reproduction in any medium, provided the original author and source are credited. 